\title{
LOS TOBAS DE LA CIUDAD DE RESISTENCIA: EL DESAFÍO DE VIVIR
} EN LOS MÁRGENES

\section{Graciela B. Guarino}

Profesora en Historia (U N N E) y maestranda en Antropología Social (U N aM ). Profesora adjunta en la cátedra de Introducción a las Ciencias Antropológicas, Facultad de H umanidades (UNNE).

Cuaderno U rbano N 5, pp. 35-54, Resistencia, A rgentina, Junio 2006 


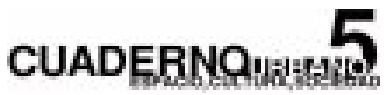

Los Tobas de la Ciudad de Resistencia: El Desafío de Vivir en los Márgenes

\section{Resumen}

Esta investigación está relacionada con el proceso de urbanización de una comunidad toba, instalada en un área marginal de la ciudad capital de la provincia del Chaco. El objetivo es describir y analizar las conductas adaptativas para la subsistencia, en el contexto de su incorporación a la vida urbana. Para estos grupos migrantes que devienen de una estructura agraria en crisis del interior provincial, la ciudad representa la posibilidad de trabajo, y el acceso a bienes o servicios novedosos. Pero también es un ámbito complejo y dinámico que provoca una tensión cultural y plantea situaciones problemáticas que los tobas enfrentan desde su posición social de pobres y su realidad étnica.

\begin{abstract}
RESISTENCIA CITY'S TOBA COMMUNITY: the challenging conditions of living marginally

This paper describes the Toba community settlement process in the outskirt of the city in a marginal area of Resistencia capital of Chaco Province. The aim is to describe and analyse their adaptive strategies for survival in the urban fabric. They w ere basically peasants that were forced to migrate, due to therural crisis, to the city to find a living. The city represents jobs, opportunities and access to goods and services. Also it is a complex and dynamic place that creates cultural tensions and unknow $n$ issues for them. M ore over the Toba community face new challenges from a very w eak position intertwining poverty and ethnic perception factors.
\end{abstract}




\section{Graciela B. Guarino}

Los Tobas de la Ciudad de Resistencia: El Desafío de Vivir en los Márgenes

\section{INTRODUCCIÓN}

La instalación de familias tobas en terrenos fiscales suburbanos de Resistencia se originó como resultado de su migración espontánea desde algunas localidades del interior de la provincia del Chaco, a partir la década de 1950. Este fenómeno social fue provocado por la crisis agrícola-forestal de ese momento, e integra el importante movimiento demográfico detrabajadores rurales hacia los centros de servicios.

Esta investigación está relacionada con el proceso de urbanización de una comunidad toba, instalada en un área marginal de la ciudad capital de la provincia del Chaco. El objetivo es describir y analizar las conductas adaptativas para la subsistencia, en el contexto de su incorporación a la vida urbana. Para estos grupos migrantes que devienen de una estructura agraria en crisis del interior provincial, la ciudad representa la posibilidad detrabajo, y el acceso a bienes o servicios novedosos. Pero también es un ámbito complejo y dinámico que provoca una tensión cultural y plantea situaciones problemáticas.

La unidad de análisis es la comunidad toba del Barrio M apic, asentamiento espontáneo, ubicado a ocho kilómetros del casco céntrico, hacia el noroeste. Ocupa cincuenta hectáreas de tierras fiscales, inundables y cercanas al cauce del río $\mathrm{N}$ egro, identificadas catastralmente como Lote 126. Está rodeado de esteros, cañadas, pastizales y núcleos arbóreos, característicos de la selva de ribera de los ríos interiores del Chaco. El lugar comenzó a ser poblado desde fines de la década del ' 60 , por familias tobas provenientes del Ingenio Las Palmas, donde se desempeñaban como cañeros, o de las colonias rurales de Pampa del Indio. El cierre del Ingenio, la mecanización de las tareas agrícolas y la privatización de las tierras públicas del interior las conminó a inmigrar hacia los centros urbanos, como R esistencia.

El asentamiento no cesó de crecer, incorporando a familias de criollos también afectadas por la desocupación. Actual mente viven allí noventa y cuatro familias aborígenes y cincuenta y un criollas, en espacios o sectores étnicos, delimitados por la escuela y una 


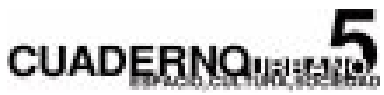

Los Tobas de la Ciudad de Resistencia: El Desafío de Vivir en los Márgenes

laguna. La lucha por conseguir los títulos de propiedad de la tierra y la pobreza son indicadores comunes que enmascaran la distancia cultural.

Diferentes programas oficiales de promoción y asistencia se han organizado en las últimas décadas, siguiendo la tendencia de la sociedad global, es decir con los objetivos de "integrar al indio" o "preservar su cultura". Pero los resultados han sido negativos, como la implementación de huertas comunitarias por ejemplo, y los proyectos se desalientan. Las entrevistas mantenidas con funcionarios del área de Desarrollo Social de la provincia, responsables de la ejecución y monitoreo de estas acciones, arrojaron conclusiones inquietantes respecto de las causas del fracaso o lentitud para lograr el desarrollo sustentable de los aborígenes. Parece primar aún la antigua idea de que éstos son poco afectos al trabajo, orden y progreso.

No obstante estas desavenencias, los aborígenes sobreviven su pobreza con empleos temporarios resultantes de las changas, ladrillerías y venta de artesanías, 0 del asistencialismo político de los planes social es. La condición de clase social excluida compromete la identidad étnica impidiendo reflexionar sobre la racionalidad y capacidad de organización social con la que asumen las tensiones y las resuelven. Es necesario construir un marco explicativo de las decisiones que sustentan las prácticas de los tobas para la subsistencia y rechaza o margina otras consideradas positivas por funcionarios y evaluadores sociales. U na línea de análisis que articula las pautas tradicionales con las condiciones de cambio cultural que genera la ciudad está constituida por las estrategias adaptativas, es decir, el conjunto de conductas adecuadas para aprovechar las condiciones naturales y solucionar problemas (Jhon W . Bennet, 1971). Estas conductas se basan en la elección y decisión de cuáles recursos utilizar, y cómo hacerlo según las preferencias o costumbres tradicional es y las posibilidades de acción.

La instalación de estas comunidades en la ciudad está atravesada por una situación social y económica: la pobreza; y además por una situación cultural: la etnicidad. Esta dualidad semanifiesta en las condiciones de su vida cotidiana porque estos aborígenes sobreviven 


\section{Graciela B. Guarino}

\section{Los Tobas de la Ciudad de Resistencia: El Desafío de Vivir en los Márgenes}

en un marco de "necesidades básicas insatisfechas" que los califica como "pobres urbanos". Y en tanto portadores de una diferencia racial y cultural, son habitantes de la otredad excluyente construida desde la sociedad global, nacional y local, por relaciones sociales asimétricas históricas.

A nivel del conocimiento y análisis de la realidad objetiva de su existencia, esa dualidad presenta complejidades teórico-metodológicas que se plantean en la decisión de abordar los asentamientos tobas como expresión sintetizadora de la marginalidad espacial, económica y socio-cultural o bien desde las interacciones que desarrolla hacia adentro y hacia afuera del espacio habitado con una dimensión a escala micro.

La primera posición "considera a la marginalidad como una resultante de la asincronía entre un proceso acelerado de urbanización y un proceso más lento y errático de desarrollo económico y social" (Bartolomé, 1984:26). Así la marginalidad no trata sólo de la pobreza en que sobreviven sino también implica su falta de participación en la toma de decisiones legitimada por la existencia de una sociedad dominante ( $G$ ermani, 1972). Con este enfoque se asume el riesgo de considerar a los tobas urbanos como un sector no integrado al sistema de clases, fuera del sistema social global en tanto pobres e indios. Pero las poblaciones nativas no están fuera del contexto social nacional y local, aunque su posición sea desfavorable por las limitaciones materiales de desarrollo y participación respecto de otros sectores de la sociedad.

La segunda perspectiva adoptada en este trabajo permite anal izar las condiciones de pobreza de los tobas urbanos, desde el sistema de relaciones en el que están insertos y sus prácticas de subsistencia, consideradas como estrategias adaptativas. "Estas estrategias adaptativas se inscriben dentro de nichos específicos que el ecosistema urbano provee. El objetivo común es el de minimizar la inseguridad, reducir la incertidumbre y maximizar la utilización de los escasos recursos disponibles" (Bartolomé, 1984:27). 


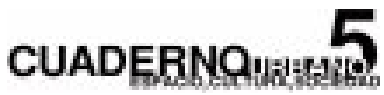

40

Los Tobas de la Ciudad de Resistencia: El Desafío de Vivir en los Márgenes

En la propuesta que se presenta, las estrategias adaptativas tienen dos ejes de desarrollo:

1. La adaptación al entorno como proceso dinámico, que compromete decisiones y elecciones entre distintas al ternativas de subsistencia.

2. La contextual ización de las conductas adaptativas, integrando las actividades específicas en el marco social y cultural del grupo.

La contextualización de las conductas adaptativas es una tarea metodológica dirigida para explicar sus causas o efectos por medio de la significación cultural que el grupo construye sobre el espacio habitado. Las construcciones culturales sobre el ambiente y sus recursos potenciales se realizan sobre informaciones e interpretaciones convencionales.

\section{EL CONTEXTO DE LA MIGRACIÓN TOBA}

El desplazamiento y radicación de los tobas en las zonas periféricas de la ciudad de Resistencia, hacia la década de 1950, fue un hecho espontáneo relacionado con la crisis agrícola-forestal que azotó el interior del Chaco. La actividad taninera y la cosecha del algodón eran los pilares de la economía chaqueña, pero con la caída de los precios y la falta de demanda externa se iniciaron tiempos muy difíciles para los pueblos del interior y sus productores agrícolas. Los criollos y aborígenes colonos, jornaleros y obrajeros, se movilizaron hacia las ciudades en busca de trabajo y mejores condiciones de vida provocando en ellas un importante impacto demográfico y espacial .

Resistencia se constituyó en un centro de atracción para esta migración rural, debido a su jerarquía administrativa y funcional, como capital provincial, que la proyectaba como un polo de desarrollo económico. A demás, el impulso de la colonización oficial estimulando el arraigo en el interior había comenzado a cesar en favor de la privatización de la tierra pública. U na nueva política regía estas adjudicaciones privilegiando la venta de cientos de hectáreas para explotaciones agrícolas o ganaderas antes que las concesiones para 


\section{Graciela B. Guarino}

\section{Los Tobas de la Ciudad de Resistencia: El Desafío de Vivir en los Márgenes}

poblar como se habían realizado en las primeras décadas del siglo XX. Y una vez más, las comunidades nativas fueron desalojadas hacia zonas marginales o suburbanas.

Esta complejidad de la situación provincial fue el contexto en el que se produjeron las migraciones de familias tobas hacia Resistencia y deben ser analizadas en el marco de ese proceso en el cual incidieron aspectos económicos, políticos y administrativos. En este capítulo se los identificarán y analizarán con la intención de recrear las condiciones y expectativas que acompañaron a los grupos aborígenes en su decisión de migrar.

La década de 1950 es un hito en la historia local por la trascendencia de los acontecimientos ocurridos, que otorgaron a ese tiempo una doble significación. Por un lado, los economistas y geógrafos identifican esta fecha con el comienzo de la crisis agrícola-forestal, su impacto en la estructura demográfica y la creciente ocupación espacial urbana. Y por el otro, en 1951 ocurrió la ansiada provincialización del Chaco, acontecimiento que comprometió el ejercicio de la autonomía política y administrativa.

Fueron las localidades del frente al godonero las que sintieron el impacto del éx odo cuando hacia 1950 el mercado nacional se saturó de esta producción sobreviniendo la caída de demanda y precios. Criollos y aborígenes partieron hacia Resistencia, capital de la provincia del $\mathrm{Chaco}$ recientemente constituida, buscando trabajo en las diversas actividades, comercial, industrial y administrativa, que la ciudad estaba desarrollando.

Por falta de infraestructuras y planificación para absorber la sobrecarga humana, el avance de la urbanización se produjo por ocupación espontánea de tierras fiscales con viviendas precarias. N uevamente son los censos los instrumentos de medición que ayudan a verificar la tendencia de este movimiento del campo a la ciudad, que significó para Resistencia su tercera etapa de crecimiento demográfico y expansión espacial hasta constituir un eje continuo con la ciudad-puerto de Barranqueras y de Vilelas. 


\section{CUADERNQuat: 5}

Los Tobas de la Ciudad de Resistencia: El Desafío de Vivir en los Márgenes

\begin{tabular}{llll}
\hline Localidades & $\mathbf{1 9 4 7 *}$ & $\mathbf{1 9 6 0}$ & $\mathbf{1 9 7 0}$ \\
\hline Resistencia & 52.385 & 108.287 & 124.497 \\
\hline Roque Sáenz Peña & 23.100 & 34.381 & 38.620 \\
\hline Las Palmas & 4.358 & 3.590 & 3.317 \\
\hline Pampa del Indio & Sin registro & 1484 & 881 \\
\hline M argarita Belén & Sin registro & 1711 & 1173 \\
\hline
\end{tabular}

*Registro censal para ciudades con más de 2.000 habitantes.

Fuentes: -Censo Nacional de Población 1960. Tomo VI. Dirección Nacional de Estadística y censos.

Maeder, J.A. y Gutiérrez, R. ,2003: 72 y 84.

El asentamiento más poblado en R esistencia es el Barrio Toba ubicado en ruta $11 \mathrm{~km} .1000$, sobre terrenos del ex Ferrocarril General Bel grano. Se inició espontáneamente hacia 1947 con la llegada de un grupo de tobas que habían migrado del Ingenio las Pal mas, Pampa del Indio, M argarita Belén (H ermitte, 1995: 163-164). H acia 1970, según un censo confeccionado por la Cruz R oja, el barrio tenía una población de 931 personas, de las cuales el $65 \%$ era aborigen y el resto criollo.

El barrio M apic, unidad de análisis de esta investigación - ubicado en tierras fiscales hacia el noroeste de la ciudad de R esistencia - comenzó a recibir migrantes tobas hacia 1966 pero luego el lugar fue abandonado porque las familias se unieron al Barrio Toba, beneficiado por un plan de viviendas construidas por el Estado provincial. U n nuevo movimiento poblacional ocurrió en la década de 1970, cuando el ingenio Las Palmas cerró sus puertas y sus tierras se vendieron. Desdeentonces el asentamiento creció con la incorporación de parientes y familias criollas, también afectadas por la crisis agrícola de la provincia.

La falta de una publicación oficial con los datos actualizados sobre la población aborigen en la provincia del Chaco dificulta el análisis de este fenómeno social y la comprensión de su magnitud. Pero en el caso de Resistencia, existe en el municipio un relevamiento socio-ambiental dirigido para cumplimentar procedimientos administrativos para la subdi- 


\section{Graciela B. Guarino}

\section{Los Tobas de la Ciudad de Resistencia: El Desafío de Vivir en los Márgenes}

visión de lotes y adjudicación de viviendas a cada familia. Allí aparecen nuevos enclaves periurbanos aborígenes, constituidos en los últimos diez años y siguiendo el patrón de asentamiento conocido, es decir en tierras fiscales, a la vera de las rutas de acceso a la ciudad, 0 en las viejas vías del ferrocarril, o en cercanías de viejos barrios donde viven sus parientes, como el barrio Toba.

Este proceso de urbanización que continúa en la década de 1990, a diferencia del iniciado en 1950, tiene la particularidad de ser resultado del crecimiento natural de la población aborigen. Como los terrenos donde se establecieron están limitados por zonas anegadizas 0 por propiedades privadas, las comunidades no pueden extenderse espacialmente. $Y$ cuando las generaciones jóvenes forman una nueva familia deben buscar otros lugares donde levantar sus viviendas, renovándose de esta manera el proceso de urbanización. Por esto en esta etapa los asentamientos que se forman son, en general, producto de relocalizaciones más que del éxodo desdeel interior provincial.

El barrio Toba está atravesando este fenómeno, que ya dio origen a dos nuevos enclaves en sus cercanías, reconocidos con las nominaciones de: barrio Los C amalotes y barrio C helliyí. El relevamiento municipal sobre los vecinos aborígenes de esteúltimo asentamiento muestra que tod os tienen una antigüedad de residencia de 2 años al 2000, y además las edades corresponden, mayoritariamente, a personas que tienen entre 25 a 40 años. Con estos datos se procedió a realizar un trabajo de campo que verificó las precarias condiciones materiales de vida, y la existencia de relaciones parentales entre estas jóvenes parejas y los vecinos del barrio Toba.

\section{BARRIO MAPIC:LA COMUNIDAD}

U $n$ total de 97 familias tobas y 15 criollas viven en la comunidad reconocida como barrio M apic, que en lengua toba significa "algarroba". Es un asentamiento espontáneo que data de 1966 cuando un grupo de siete familias aborígenes migró desde la localidad de 


\section{CUADERNQU1A: 5}

44

Los Tobas de la Ciudad de Resistencia: El Desafío de Vivir en los Márgenes

Pampa del Indio, pero luego abandonó el sitio, que fue repoblado por otras familias tobas migrantes desde las chacras del Ingenio Las Palmas, en 1972.

Se encuentra ubicado hacia el noroeste de la ciudad de Resistencia, a una distancia de ocho kilómetros. Pertenece al espacio suburbano, y la superficie total del lote fiscal es de 55 hectáreas. Forma parte de la antigua cuenca inundable del río Negro, afluente con dirección noroeste-sudeste que atraviesa varios munici pios, entre ellos R esistencia, y luego desemboca en el riacho Barranqueras, para terminar en el Paraná.

El barrio tiene un desarrollo longitudinal y paral elo a la ruta nacional N icolás Avellaneda, de la que dista unos 1000 metros, por camino de tierra. Está dividido en dos sectores étnicos, los tobas y los criollos, que tienen como lugar común el edificio educativo, EG B

Vista aérea del barrio Mapic (1997).

Fuente: Unidad Ejecutora de Proyectos, Municipalidad de Resistencia.
963. Cuenta con luz eléctrica, pública y domiciliaria, y dos canillas de agua corriente para uso comunitario. El C entro de Salud, atiendeen horario diurno, emergencias y acciones

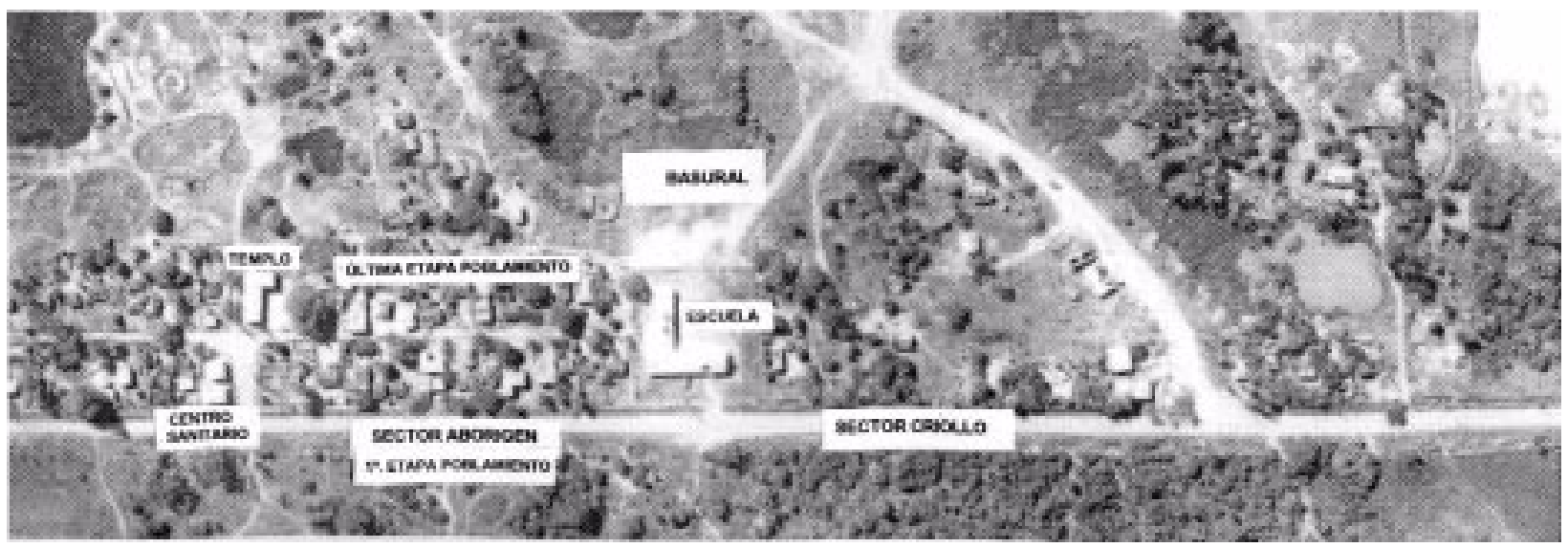




\section{Graciela B. Guarino}

\section{Los Tobas de la Ciudad de Resistencia: El Desafío de Vivir en los Márgenes}

de prevención, y el comedor comunitario fundado y dirigido por la Cruz R oja da refuerzo alimentario a 200 niños de todo el barrio y zonas cercanas.

El asentamiento, cercano al cauce principal del río N egro, está en una zona de esteros y cañadas, con pastizales y núcleos boscosos. De allí obtienen la materia prima para sus artesanías, leña para sus fogatas, peces y aves. El caudal de información sobre el valor de las especies, transmitida por sus antecesores, no puede utilizarse en extensión porquelas condiciones del hábitat se han modificado. Esta situación los lleva a adecuar sus acciones con las posibilidades del medio, no en sentido determinista, sino en orden para seleccionar recursos y el egir su proceso de transformación. Si bien la pobreza y limitaciones en que viven hacen suponer queoptimizarían el uso derecursos naturales disponibles y deciertas actividades económicas subsidiarias de ellos, para los tobas, en la explotación del entorno se conjugan saberes empíricos tradicionales con normas adquiridas en el transcurso desu historia.

$\mathrm{H}$ ace seis años este asentamiento era reconocido por su cercanía a uno de los mayores basurales de la ciudad. Los constantes reclamos de familias aborígenes a las autoridades municipales para erradicar la acumulación de residuos, resintió profundamente la relación con sus vecinos criollos. Esta observación no pasa inadvertida cuando se describen las actividades para la subsistencia. Porque el impacto que los desperdicios tuvieron, y aún tienen, sobreel medio ambiente es diferencial mente valorado por aborígenes y criollos. U na consecuencia lamentable es la contaminación de los espejos de agua lindantes con las viviendas. No es apta para el consumo humano, pero sí para los animales de crianza, huertas familiares y otros usos domésticos, costumbres desdeñadas por los tobas.

Entre las razones que distancian a criollos de aborígenes, sobresalen sus diferentes estrategias para la ex-

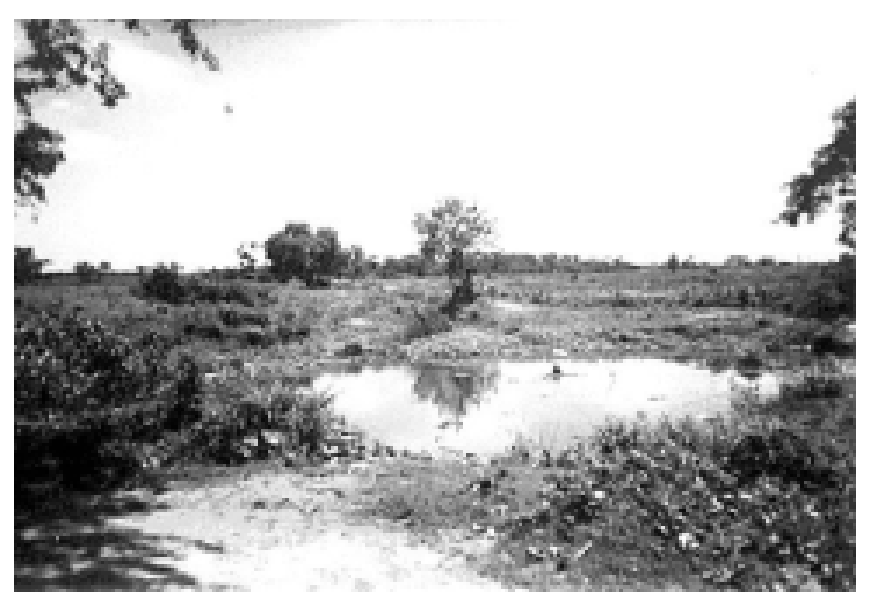




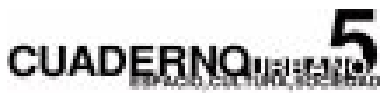

Los Tobas de la Ciudad de Resistencia: El Desafío de Vivir en los Márgenes

plotación de recursos. Las familias criollas sobreviven a la pobreza aprovechando intensivamente los materiales de desecho, que seleccionan del basural y destinan para construir sus ranchos, cercos, al imentar los cerdos, y aves de corral, como para la venta de lo reciclable. De las cincuenta y un que habitan el barrio, tres han iniciado huertas para el consumo doméstico, dos crían cerdos y gallinas, dos tienen ladrillerías y el resto hace changas en la ciudad. Pero todas hacen uso del basural y extraen agua de los pozos y esteros. Sus viviendas son precarias, tipo rancho, con letrinas, cercadas con palos, o cartones. En los patios, seacumulan los desechos elegidos para aquellos fines mencionados, al gunas mesas y sillas.

En igualdad de situación social, con necesidades básicas insatisfechas, los tobas resuelven los problemas de subsistencia de manera diferente. Sus viviendas son de tipo rancho con techo de chapas, cercadas por tacuaras y plantas arbustivas, tienen letrinas que llamativamente se encuentran ubicadas hacia el frente, en los solares que están sobre el acceso de ingreso al barrio.

Respecto de los ingresos económicos, al rededor de cuarenta familias aborígenes están incluidas en el Plan Jefas y J efes de Hogar, otorgado por el gobierno nacional; hay veinte artesanos y la mayor parte de las mujeres confecciona canastos de paja y totora, para vender. Predominan los trabajos temporarios, como albañiles de obras en construcción, carga y descarga de camiones, pesca de morenas y cascarudos para carnadas.

No hay huertas domésticas, sólo dos familias tienen aves de corral, rechazan el basural y todo lo relacionado con él. Por esta razón no utilizan el agua de pozos ni esteros, aduciendo que está contaminada. Ante una verificación de esta condición del agua, en Sanidad Ambiental de la administración municipal se constató que los análisis técnicos realizados en 1990 determinaron que, efectivamente, el agua no era apta para el consumo humano.

Respecto de la alimentación, los tobas complementan su dieta, básicamente, con hidratos y grasas (fideos, frituras, guisos), con proteínas que obtienen de la caza de animales. Por ejemplo el coatí, el avestruz y el guasuncho. La pesca no es explotada como fuente de 


\section{Graciela B. Guarino}

\section{Los Tobas de la Ciudad de Resistencia: El Desafío de Vivir en los Márgenes}

alimentación, sólo para la venta. Un dato auxiliar es la recolección de leña para la cocción de alimentos, tarea rutinaria que realizan hombres y mujeres, en grupos de seis 0 siete, durante las horas de la tarde, en los montes cercanos.

\section{LA PERCEPCIÓN DEL HÁBITAT}

A pesar de que las condiciones de la vegetación y fauna chaqueña se han modificado, y de los ingentes esfuerzos oficiales por la aculturación agrícola de los aborígenes, los tobas mantienen un sentido práctico de subsistencia. Siguiendo a Bennett (1971: 11-15) podemos adelantar que sus estrategias adaptativas, para aprovechar las potencialidades del medio ambiente, se realizan sobre procesos sel ectivos de recursos naturales y fines, e implican tomar decisiones respecto de las acciones más adecuadas.

Los tobas tienen un sentido amplio del hábitat, que desborda el espacio del asentamiento. El barrio es el lugar donde viven, pero conseguir el alimento o los materiales para sus artesanías los lleva a movilizarse lejos. Tienen una gran disposición para desplazarse, Ilevando sólo lo necesario y la tranquilidad de contar con la recepción de sus parientes en el interior dela provincia. El área de caza puede superar los cien kilómetros; considerando la extensión en rutas pavimentadas, abarca las localidades de Colonia Benítez, Las Palmas, General San M artín, y Fortín Lavalle. Para las artesanías, tienen una zona más reducida, porque las arcillas, totoras y palmas se encuentran en bañados o esteros cercanos a Resistencia: Fontana, Puerto Antequera y Barranqueras.

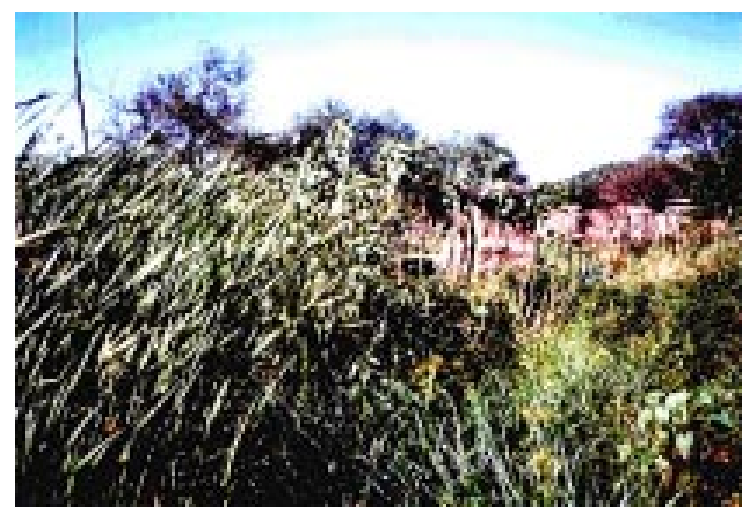

Imagen 3

Plantas de totoras cercanas a las viviendas.

Imagen 4 Hojas de totoras secas para cestería.

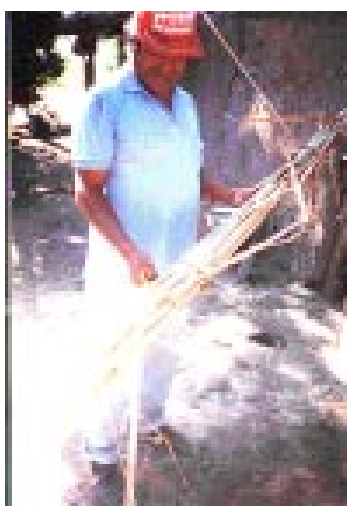




\section{CUADERNQU⿴囗十: 5}

Los Tobas de la Ciudad de Resistencia: El Desafío de Vivir en los Márgenes

Estas actividades siguen esquemas sociales y culturales de probada eficacia por la tradición. Así, la caza se realiza en grupo, de tres o cuatro varones adultos, entre ellos un baqueano, es decir, un cazador experimentado en rastreo de presas. Los días con intenso viento norte son los preferidos para cercar avestruces porque dispersa los olores que guían al animal. Los hombres se internan en los pajonales, y se camuflan con hojas hasta unos cinco pasos del animal, y disparan. A demás de consumir la carne del avestruz, comercializan sus plumas en el mercado local, a \$25 el kilo, cantidad que se puede obtener de un animal grande. La única limitación para la cacería son los campos cercados, y la protección de especies que realiza la Dirección Provincial de F auna, Parques y Ecología.

La selección de material es requiere de experiencia porque no todas las totoras o palmas tienen cualidades para la cestería. R econocen las aptitudes de las fibras por el tacto. La recolección comienza en octubre, cuando los tallos están verdes y flexibles. Se los deja secar dos o tres días con buen sol, una noche al rocío y en la mañana con las fibras ya separadas, se procede a entrecruzarlas sobre las rodillas, hasta conseguir las distintas formas deseadas (canastos, sombreros, adornos).

En la cerámica incorporaron novedades técnicas como de diseño. M ezclan la arcilla con aserrín, la secan al sol y pintan con acrílicos. También confeccionan arcos y flechas para vender. U tilizan la madera de guayaibí y el garabato porque son resistentes a la tensión del cordel.

Este conocimiento de los recursos del hábitat y sus cual idades forma parte de la herencia cultural toba. Pero se debe tener en cuenta que tanto la modificación ambiental como existencial que les impone la urbanización, los limita en sus posibilidades de acción. Tener datos sobre cantidad y calidad de los recursos facilitalatoma dedecisiones y previsiones.

La circulación de información, para los tobas del Barrio Mapic, tiene dos canales: las ferias artesanales, que los reúne con frecuencia, y las visitas a parientes. Estos encuentros permiten el intercambio y organización de actividades conjuntas, como las cacerías, y aquella 


\section{Graciela B. Guarino}

Los Tobas de la Ciudad de Resistencia: El Desafío de Vivir en los Márgenes

información útil que advierte sobre cambios en las condiciones del medio, por ejemplo contaminación, desmontes, sequía.

\section{LA RACIONALIDAD EN EL USO EXTENSIVO DE RECURSOS}

Como ya se adelantó, los tobas viven y se movilizan conforme con un concepto amplio de hábitat y de relaciones parentales, que les facilita la explotación extensiva de su medio. Según Elmer M iller (1979: 165), el deseo de restablecer una relación armónica con la naturaleza - alterada por la colonización blanca - motiva a los tobas hacia ese tipo de explotación, que exige menor cantidad de energía en la obtención de recursos. Esta afirmación que el autor realiza como resultado de sus trabajos de campo a comienzos de la década del '70, tiene un marco de aplicación interesante en la comunidad toba del barrio M apic, y puede ser ampliada con otros factores explicativos, más orientados sobre el sentido práctico en la explotación del ambientey los valores sociales.

Los integrantes de estas familias trabajaban como asalariados del Ingenio Las Palmas, hasta que migraron hacia Resistencia. Tenían pequeñas chacras para el consumo doméstico, y conocen las fluctuaciones de las políticas agrarias porque ellas son sus víctimas. Cuando se instalaron en la zona suburbana, recibieron lotes de $50 \mathrm{mts}$.por $100 \mathrm{mts}$. de extensión, cada familia. U na superficie que les permitiría poseer una pequeña huerta. No lo hicieron entonces, y aún mantienen esa decisión. Las justificaciones que aducen reveIan una racionalidad definida por valores culturales y sociales (según $\mathrm{M}$ ax W eber, «substantive rational ity». Bennet, 1971: 17). En afán de sistematizarlas, serían las siguientes:

* Conocimiento empírico de la relación costo-producción: según su experiencia, el ciclo agrícola de cualquier especie requiere de un trabajo que insume, en el mejor de los casos, dos meses hasta la cosecha. La producción de una huerta no alcanza para satisfacer las necesidades básicas de un grupo familiar, con promedio de siete personas, y para el caso de huertas comunitarias, sería necesario limpiar los pajonales, talar los árboles, erradicar los tacurúes y rellenar las zonas bajas del 


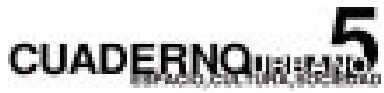

50

Los Tobas de la Ciudad de Resistencia: El Desafío de Vivir en los Márgenes

lote fiscal que habitan. Un trabajo de mantenimiento constante y sin retribución para alimentar a 94 familias (aproximadamente 600 personas).

* Asimilación de conceptos ecológicos: el impacto del basural sobre el agua y la tierra los inclina a considerar la contaminación como un obstáculo para las prácticas agrícolas. Este aspecto que bien podría ser una influencia de informaciones impartidas por la escuela donde un equipo docente fomenta las huertas y la alimentación equilibrada, también tiene relaciones con la percepción cultural de la

Imagen 5

Paisaje característico del barrio Mapic.

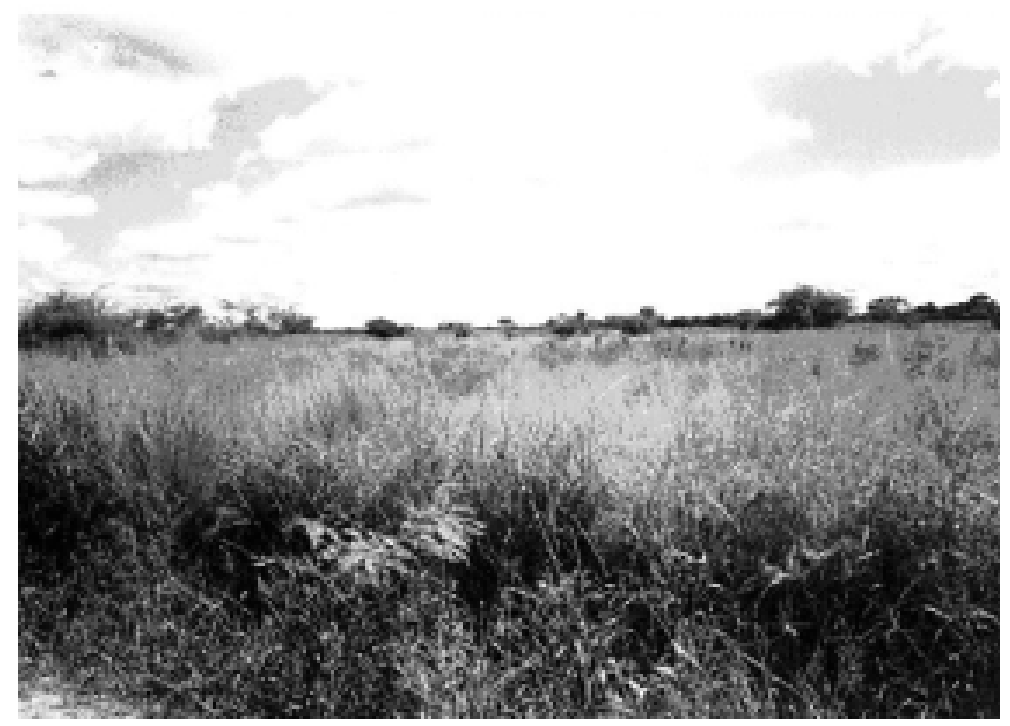
natural eza. La representación tradicional de un estado necesario de armonía entre el hombre y su ambiente implica una comunicación constante, individual y colectiva para evitar una alteración o al menos ser concientes de las causas que lo provo-

can. Los espejos de agua presentes en el espacio del barrio no son naturales sino producto de la mano del hombre blanco que extrajo de allí grandes cantidades de tierra para construir la defensa urbana contra inundaciones. Su nivel se debe a las Iluvias o ascenso de las napas, contaminadas por el basural.

* Los compromisos del parentesco: si bien inicialmente los lotes tenían las dimensiones mencionadas, con el tiempo debieron agrandar las viviendas para recibir a los parientes que llegaban desde el interior en busca de asentamiento, o para los hijos recién casados. Al distribuir los solares, tuvieron en cuenta que la organización del espacio no impidiera el cumplimiento de estos compromisos sociales. Por esto, actualmente cada familia habita un lote reducido a 


\section{Graciela B. Guarino}

Los Tobas de la Ciudad de Resistencia: El Desafío de Vivir en los Márgenes

$10 \mathrm{mts}$. por $50 \mathrm{mts}$., con un patio amplio y destinado a las tertulias del grupo. Además, con la organización social del parentesco extendido - que aún perdura- aumentan las demandas alimenticias, que no se podrían asumir con el rendimiento de una pequeña huerta.

Las artesanías, la caza o la pesca, en cambio, son apreciadas por ser actividades de resolución más rápida, e independientes de los cambios climáticos. Además acostumbrados a desplazarse, la venta de aquellos objetos les exige movilizarse por distintos puntos de la ciudad, con gran libertad de horarios, e incluso participar de ferias interurbanas. A través de ellas la comunidad mantiene vigentes los lazos de parentesco y solidaridad, mientras intenta mantenerse dentro de la economía de mercado. En el proceso de urbanización que sobrellevan, las familias tobas revalorizan el sentido práctico de la explotación de recursos, que tradicionalmente los caracterizó. N o tratan con ello de minimizar esfuerzos, sino riesgos, en razón de respetar las pautas culturales y sociales, tanto como el éxito en la subsistencia.

\section{CONCLUSIONES}

Cuando la investigación se centra en la integración de las comunidades aborígenes al medio urbano, existe el riesgo de minimizar el val or de las expectativas étnicas y sus concepciones tradicionales en ese proceso de cambio cultural. Las descripciones y análisis sobre los tobas urbanos o urbanizados, en general, sintetizan sus características identificándolos como marginales y asalariados no calificados. Esta categorización disuelve la identidad cultural de las comunidades tobas, su existencia.

Sin negar el impacto cultural que provoca la urbanización en el estilo de vida tradicional de los tobas, el anál isis de sus actividades de subsistencia debería incorporar los factores que promueven la permanencia de ciertas prácticas económicas, 0 al menos la tendencia a que éstas persistan. Las expectativas de quienes proyecten acciones de promoción comunitaria, gestionadas en el marco de políticas sociales y bajo la urgencia de conseguir resultados no pueden desconocer la racionalidad de las estrategias que los tobas, urbanizados, elaboran según su horizonte cultural y empírico. 


\section{CUADERNQU⿴囗十: 5}

Los Tobas de la Ciudad de Resistencia: El Desafío de Vivir en los Márgenes

Para el caso que analizamos, esos factores se traducen en valores culturales y sociales, que modelan la forma de comprender la relación costo-beneficio en la explotación de recursos. U na relación construida sobre la valoración de la naturaleza como productora de bienes tanto como sobrela responsabilidad de saber lo queel grupo necesita para sobrevivir.

Al mismo tiempo, y en dirección dialéctica, la percepción de un hábitat extendido, por el conocimiento empírico de sus aptitudes y la transferencia de informaciones útiles, afianza los lazos de parentesco y cooperación. La incorporación al sistema capitalista no ha logrado aún destruir estas relaciones, aunque la familia nuclear como unidad de reproducción económica se perfile como la agrupación sobreviviente por sobre la tradicional familia extensa. M ás aún considerando que los loteos, las adjudicaciones de títulos y viviendas las tienen como ejes de la acción pública.

Pero aún siendo así, elegir entre distintas alternativas de subsistencia es una decisión compleja, porque en las prácticas de cada unidad familiar se involucran representaciones colectivas fuertemente enraizadas en el pasado cultural de la comunidad. Además en el proceso de urbanización, la conciencia étnica subraya la pertenencia al grupo, enfatiza las diferencias con la sociedad global y amortigua los efectos de la exclusión.

\section{BIBLIOGRAFÍA}

AGU ADO, R. Y M . PORTAL. ( 1991) Tiempo,espacio eidentidad social. En:Alteridades. 1(2):31-41 AU GE, M arc. (1995) Hacia una A ntropología delos mundos contemporáneos. Barcelona: ed. G edisa. BARTOLOM E, Leopoldo. La familia matrifocal en los sectores marginados: $D$ esarrollo y estrategias adaptativas. En: R evista R U N A N XIV, Buenos Aires, U B, 1984.

BEN N ET, John W . (1971) A daptation as a frame of reference. En: aut. Cit. N orthern Plainsmen. Adaptative Strategy and Agrarian Life. Chicago: Aldine.

BOR DIEU , Pierre. ( 1979) $O$ D esencantamento do M undo: estruturas económicas eestruturastemporais. San Pablo, Brasil, ed. Perspectiva.

GEOGRAFICA. (1990) Revista del Instituto de Geografía. Facultad de Humanidades. UN NE, R esistencia. $N$ ำ, tomo III. 


\section{Graciela B. Guarino}

Los Tobas de la Ciudad de Resistencia: El Desafío de Vivir en los Márgenes

GER M AN I, Gino. (1973) El concepto deM arginalidad. Buenos Aires, N ueva Visión.

HARDESTY, Donald L.(1979) A ntropología Ecológica. Barcelona: Bellaterra.

HERM ITTE, Esther ( 1991) Situación dela población aborigen dela provincia del Chaco y políticas para su integración a la comunidad nacional. Posadas, U N AM .

M ILLER, Elmer ( 1979) Lostobasargentinos. A rmonía y disonancia en una sociedad. M éxico, ed. Siglo $X X I$.

M ORELLO, Jorgey HORTT, Guido. (1998) U so sostenibledelosecosistemas naturales y productivos. Resistencia: UNNE.

M ORDO, Carlos (2001) D esarrollo local: los pueblos indígenasen la encrucijada. En: Burin, David y Heras, A na (Comp.). Desarrollo Local, Bs. As., ed. Ciccus.

NYER GES, EndreA. (1995) Introduction. TheE cology of Practice. En: The Ecology of Practice. Studies of food Croop Production in Sub-Saharan W ets Africa. Amsterdam: Overseas Publishers Association.

W YNAR CZYK, Hilario (1988) Los tobas. Un estudio de tres comunidades. En: Suplemento Antropológico, Bs. As., Vol. XXXI, $\mathrm{N}^{\circ} 1$ y 2. 
